\title{
Safety Nets and Retirement Preparations of Teachers in Nigerian Schools
}

\author{
Subair, S. 'Tayo*, Olusegun Oluwadamilola C, Aliyu, M. Olasunkanmi \\ Department of Educational Management Faculty of Education Obafemi Awolowo University Ile-Ife, Nigeria \\ *Corresponding Author: Subair, S. 'Tayo, Department of Educational Management Faculty of \\ Education Obafemi Awolowo University Ile-Ife, Nigeria
}

\begin{abstract}
The study assessed the government safety nets programmes available for teachers in schools in preparation for retirement; it examined personal safety nets of individual teachers; assessed the differences in safety nets preparation between male and female teachers; and investigated problems associated with safety nets among teachers in Nigerian schools. These were with a view to providing information on the need for government to take issue of teachers' safety nets serious and for teachers' self-retirement plans. The study adopted the descriptive design research using qualitative approach with a population of 6,982 teachers and 489 principals. The samples were 150 teachers who constituted the Focus Group and 30 principals in Osun State secondary schools using purposive sampling technique. Two instruments used to elicit information for the study were Interview Guide (IG) for principals and Focus Group Discussion Guide (FGDG) for teachers. The data collected were analyzed using content analysis to answer the research questions. The results of the analysis were presented accordingly putting into consideration the research questions. The results showed that there was no ideal safety nets programme put in place by government for teachers in Nigerian schools in preparation for retirement because there was no social package that may likely enhance living standard of the teachers while retired and to safe Nigerian teachers from social and financial embarrassment upon their retirement. Also, there was no safety net programme put in place by individual teachers because the salary to plan on was not paid as and when due. Furthermore, female teachers were a bit ready for the retirement than their male counterparts because majority of the female teachers engage in some petty trades after school hours. These trades fetch them additional income to complement irregular salary paid by State governments while the male teachers resort into farming; andthe problem associated with safety nets among teachers in Nigeriais non-observance of agreement of terms bysome state governments. The study therefore concluded that Nigerian government did not take issue of teachers' safety nets serious and it becomes necessary for the teachers to themselves prepare if their post-retirement age is to be restful, rewarding and healthy.
\end{abstract}

Keywords: Safety Nets, Retirement Preparations, Teachers, Schools

\section{INTRODUCTION}

Human resource in any country constitute the most valuable resource which ensures the usefulness of other resources and it is particularly the group of people at work comprising large number of individuals of different sex, age, socio-cultural background, religious beliefs and educational standards. These individuals exhibit a set of similar and in some cases, dissimilar behavioural patterns and characteristics to a certain degree. At the organisational level, it includes all the component resources of all employees like managing director, board of directors, persons who work on honorary basis, experts drawn from various fields and those resources of all the people who contribute their services in the attainment of organisational goals and objectives (Kasuso, 2015). Despite the myriad importance of work in the lives of human beings, workers must be disengaged at attainment of age 60 or 35 years in service, whichever comes first. It is very important therefore for any person who works to know that as soon as he or she gains employment, one day, he or she will retire and should become conscious of safety nets from the onset.

Retirement is a necessary end. Retirement means different things to different people. To some it can be exciting, delightful, pleasurable, thrilling and something to look forward to. While to some, it means the end of the road; the time of psychological stress, time of boredom and so on. Adamolekun (2011) stated that when people retire from active work role, they are clearly cut off from the benefits derived from the work culture, hence some psychological, economic, social and even health problems may occur. Retirement is the point where people stop employment completely. It signifies the 
detachment from primary activity in business, industry or active service as full-time employee. It could also be seen as the complete or partial disengagement from work or a given occupation or social life. Nwajagu (2007) sees retirement as withdrawal or giving up office or work through voluntary, compulsory and mandatory format. Whatever means it occurs; it is a transition from phase of work life to another phase of leisure activities which may not be paid for. Moser (1997) sees retirement as to withdraw from business or public life so as to live at leisure on one's income, savings or pension. $\mathrm{He}$ argues further that for retirement to be successful, prime ingredients must be present such as robust health, financial security, and the balance of intellectual, physical, cultural and social activities. Thus, retirement can and should be an exciting time. For the first time, one has the leisure and freedom to travel and do other things of interest freely.

Retirement in the school system is an official and formal ending of a work life. It is a transition from active involvement in the world of work to active world of leisure (Oladunjoye \& Omemu, 2015). However, for many teachers, retirement can be challenging because many retired teachers seem to be passing through turbulent situations. These are retired teachers who do not find new meaningful activities to replace work, there is the risk of boredom and sense of purposelessness that can lead to depression and health problems. Many are being faced with a lot of psychological problems and health challenges arising from little or no provision for safety nets.

Safety nets in the context of this study, is a system of income to help people through short-term stress and calamities. Invariably, safety nets are programs that assist those who are temporarily exposed to shocks, such as the unemployed or those who are relatively permanently incapable of participating in the productive process, such as the elderly and the disabled. Safety nets are essentially income maintenance programmes which is aimed at protecting individuals or households against inability to work and earn, and a decline in this capacity caused by imperfectly predictable lifecycle events (such as the sudden death of a bread winner), sharp shortfalls in aggregate demand or expenditure shocks (Jurado, 2001).

From the angle of government, safety nets imply any programme of support put in place to mitigate the social impact of structural adjustment measures on specific low income groups, aged, widow, retiree and many other less-privileged in the society to serve as social measures for temporal alleviation of damages caused by income risks (Subair, 2019). Safety nets programmes were formulated to serve three major objectives which are poverty alleviation, adjustment of social programmes for political acceptance and institutional reform (Vivian, 1994).

Safety nets as a government-provided anti-poverty benefit is a major element of social assistance, while social assistance is a part of social security, and social security is a part of social protection(International Labour Office, (ILO) 2000). However, from the angle of individuals, it appears necessary to examine the level of financial preparedness for retirement, as precautionary means and readiness for such stage in any employee's life. It is against this background that this study seeks to assess safety nets programmes and employee retirement preparations among public schools' teachers in Nigeria.

\section{LITERATURE REVIEW}

The term safety nets originated from a net to protect acrobat players of a circus from falling to the ground and it became frequently used in the early 1990s especially by some institutions in connection with structural adjustment programs related to their lending programs. Developing countries introduced safety nets to mitigate the social impact of structural adjustment measures on specific low income groups. From inception, safety nets programmes were formulated to serve three major objectives which are poverty alleviation, adjustment of social programmes for political acceptance, and institutional reform (Vivian, 1994). Safety nets refers to social measures for temporal alleviation of damages caused by income risks.

The World Bank (1990) defined safety nets as a system of income insurance to help people through short-term stress and calamities. It is targeted at those who are potentially able to support themselves through individual productive effort or through the assets which they own, but are temporarily unable to do so at the relevant minimal acceptable level. Jurado (2001) maintained that safety nets are programmes intended to assist people who have been unfavourably affected by shocks or other kinds of emergencies and not necessarily the poor. Jurado vividly distinguished between safety nets and other concepts as related to it such as social security, social protection and anti-poverty programmes. 
The researcher drew a line between formal and informal safety nets and maintained that safety nets should not include anti-poverty programmes. Study by ILO defined safety nets as a governmentprovided anti-poverty benefit which is a major element of social assistance, while social assistance is a part of social security, and social security is a part of social protection. The study further posited that safety nets does not include social insurance systems financed by contributions from employers (ILO, 2000).

The assessment of the Philippines' financial crises by Pasadilla (2000), shows that safety nets were introduced in form of loans, funding for displaced workers, educational, calamity and housing loans, and emergency loans. There are two major roles which safety nets programmes seek to serve. These include redistributive role (example is transfers to disadvantaged groups) and the second is insurance role (such as provision of drought relief to citizens). The redistributive role is envisioned to lessen the impact of poverty while the risk reduction role of safety nets is aimed at protecting individuals, households and communities at large against uninsured risks of income and consumption. Consequent upon this view, safety nets programmes should be specifically designed to address the needs and characteristics of various categories of a country's poor population (Paitoonpong Abe \& Puopongsakorn, 2008).

According to Teranishi (2005), safety nets has some basic characteristics. These are attributes found which safety nets programmes put in place either by the government or private social organizations. Essentially, there are three major characteristics of safety nets which are prevalence of income risks, policy tools for temporary effects, and social and market-based risk management.

1. Prevalence of income risks: Safety nets is related to prevailing high risky situations faced by individuals and the society at large. The rate of uncertainty as found with global economic activities has brought about quick and unexpected spill over of shocks over various parts of the world economy. As a result of this, safety nets programmes are planned to forestall the risks or uncertainties of probable distribution of income that may arise.

2. Temporary policy tools: Safety nets is a simple and inexpensive measure to protect people from risks, as could be seen from the fact that it is named after a simple and inexpensive instrument, a 'net'. It is a temporal means of social security to alleviate direct damages caused by shocks. As regards financial expenditures, safety nets is related to short-term expenditures and not to permanent fiscal burdens; and does not have much to do with structural problems such as inequality of income among different class of people, absolute low-income below the poverty line, or rapid aging of the society.

3. Social and market-based risk management: This is another important attribute of safety nets programmes. They are not targeted at certain professions, age or sex groups rather, they are directed to unspecified constituents of the society. Invariably, safety nets help to manage uncertainties faced by members of the society as whole.

The emergence of safety nets programmes has been traceable to period of financial crisis witnessed in Asia which led many people at a stance of vulnerability and risks against low economic performance. Consequently, structural adjustments programmes to forestall this menace sprung up and therefore serves as the justification for the inclusion of safety programmes across the world. Teranishi (2005) posited that the two major reasons that necessitate the emergence of safety nets programmes as an imperative method for social security across the globe are; individualization of the society and the globalization of market economy. Specifically, some of the reasons why safety nets become necessary include:

1. Protection against vulnerability and risk: Vulnerability arises from a complex web of economic, political and social conditions. It is a process of cumulative conditions which vary over time and space depending largely on the changing processes through which individuals, households and communities fulfil their immediate subsistence needs and invest in medium and long reproduction of their social system. In view of this, safety nets are aimed at protecting citizens against vulnerability and risk of any kind ranging from vulnerability to income, poverty, malnutrition, or natural disasters, which may affect different people in different ways, times and magnitudes (Gentilini, 2005).

Gentilini further identified three techniques of managing risk with the help of safety nets programmes to include: prevention, mitigation and coping. Preventive safety nets programmes 
reduce the probability of the shock from occurring, whereas mitigation safety nets strategies are aimed at reducing the potential impact of the shock when risk occurs. Coping strategies are also undertaken to relieve the impact of shocks once they occurred.

2. Globalization: According to Teranishi (2005), globalization is a necessity for safety nets and has manifested in two ways. First, globalization seems to have enhanced income risks to be accommodated socially; and as a result of increased interdependence of financial markets, local financial crises tend to have global impacts. The Asian financial crisis that emerged in Thailand in 1997 had serious widespread effects on other Asian countries, and the Lehman shock ten years after had exerted enormous impacts throughout the world. These global financial crises tend to demand income risks to the plural strata of people, such that its impacts become a social phenomenon. This crisis does not only have impacts on the financial markets but also on the goods markets by way of decrease in exports, labour markets by way of impacts on oversees job opportunities, and government budget through reduced tax revenues. Income risks under these conditions need to be accommodated socially.

3. Socio-economic and political inclusion: Gentilini (2005) in his own view submitted that safety nets arrangements could facilitate and promote the socio-economic and political inclusion of marginalized groups. Shepherd (2004) also noted that safety nets need to include measures that improves the chances that individuals and households will be in a position to contribute positively in future to the economy.

4. Economic trends and the changing nature of work: The rapid change in economic trends and the incessant change nature of work is another necessity that justifies the inclusion of safety nets programmes in any society. Lop rest and Nightingale (2018) posited that wages are stagnant for many workers (especially less educated, low-wage workers), increasing numbers of workers are out of the labour market, and access to employer-sponsored benefits is declining by the day. In real terms, growth in hourly wages for workers in the middle or bottom of the wage distribution has been relatively flat and economic returns have been concentrated among those with higher levels of education.

Declining labour force participation is affected by many complex factors, such as changing population demographics (e.g., aging and retiring groups), global competition and industrial composition, shifting immigration patterns, and technological advances. Some people eventually rotate in and out of the labour market, others are more chronically not employed, and some may be in the informal economy (Loprest\& Nightingale, 2018).

In addition, Gentilini (2005) asserted that safety nets frameworks in developing countries are premised on three basic pillars which are social prevention, social insurance and social assistance. Social prevention policies comprise the set of instruments aimed at both preventing risks from occurring and creating the legal environment for social and economic development.

Safety nets can be classified into two major types based on the programme. This include formal and informal safety nets. Generally, formal and informal safety nets are distinguished by the fact that one is supported by statute while the other is not. Formal safety nets are those which legally guarantee individuals access to economic or social support; however, informal safety nets provide a possibility of support to individuals to assure them of attaining the minimum standard of living but are not legally mandated. In addition to this, safety nets can also be classified on the basis of its finance. This include public safety nets and private safety nets. Public safety nets are the structural adjustment and lending programmes financed by the government. On the other hand, private safety nets include private, informal, community-based arrangements that help mitigate against deprivation and temporary income shortfalls.

Beegle, Honorati, and Monsalve (2018) further submitted that safety nets are non-contributory programmes targeting the poor or vulnerable. They may be designed, implemented, and supported by governments, international organizations, or non-governmental organizations (NGOs). Their distinctive feature is their non-contributory nature, that is, beneficiaries do not have to contribute financially to receive the benefits.

A study conducted by Aiyede, Sha, Haruna, Olutayo, Ogunkola\& Best (2015) in Nigeria posited that social assistance which is a subset of safety nets programmes entered the Nigeria policy agenda in 
2004, but governments have been slow to adopt social assistance as a major redistributive programme in spite of the deepening poverty profile. Programmes have been extremely narrow and temporal. Nigeria's investment in social assistance has been quite insufficient at 0.001 percent of the GDP. Cash transfer programmes have remained largely at the pilot stage. Constitutional provisions and Nigeria's commitment to international covenants and conventions on social policy issues have not translated into enthusiasm in adopting social assistance measures. This is partly because the dominant view in public policy is that poverty is caused by lack of growth. Secondly, the national vision of the economy sees the private sector as the engine of growth. Thus, entrepreneurship development has permeated every effort of poverty alleviation.

The study also found that the constraint to constitutional provisions that explicitly require government to carry out social assistance programmes is the fact that the provisions are non-justiciable in Nigeria. There has not been any significant movement whether in government or civil society mobilising for their justifiability as has happened in India. Donors have been key promoters of social assistance in Nigeria especially providing technical assistance to the federal government in policy and programme development. The perceived instrumentality of social assistance as political good in some states has thrown it into the partisan policy arena but an uptake can only happen if one or two states are able to experiment with larger transfer programmes and demonstrate their relevance for election purposes and for poverty alleviation.

\section{Statement of the Problem}

Retirement in the school system is an official and formal ending of a work life. It is a stage of working life that separates a worker from his or her job role to enjoy leisure and freedom from job demands. Ideally, retirement does not mean the end of one's world rather the beginning of a new world or another phase of life in which retirees are expected to enjoy social programme put in place by government to protect them from financial risks. Contrary to this, observations have shown that many teachers' retirement appears to be full of dreadful experience; hence, it seems to appear as a threat to many employees rather than an issue of interest. This seems due to the failure on their part to make preparations for retirement and inability of the government to provide structural adjustment measures that could help alleviate the damages that could be caused by income risks. Arising from this fear of unknown and the desire to maintain the status quo, it is anticipated that most teachers should embark on self-safety nets plans. It then becomes expedient to empirically assess the safety nets programme and retirement preparations among school teachers in Nigeria.

\subsection{Research Questions}

The following questions were raised to guide the study:

1. What are the government safety nets programmes available for teachers in schools in preparation for retirement?

2. What are the personal safety nets of individual teachers in Nigerian schools?

3 What are the differences in safety nets preparation between male and female teachers in Nigerian schools?

4 What are the problems associated with safety nets among teachers inNigerian schools?

\section{Methodology}

The study adopted a descriptive research design using qualitative approach. The population for this study comprised 6,982 teachers and 489 principals in 489 public secondary schools spread across the three Senatorial Districts in Osun State. (Source; Ministry of Education, Osun State, 2019). The sample for this study comprised 150 teachers and 30 principals. The Multi-stage sampling procedure was used for selecting the sample. Being a qualitative study, the sample frame was considered adequate enough to guarantee required information for the study. Two sets of self-designed instruments entitled: Safety Nets and Retirement Preparations Interview Guide (SNRP-IG) and Safety Nets and Retirement Preparations Focus Group Discussion Guide (SNRP-FGDG) were used to elicit information for the study. The credibility of data obtained was ascertained by subjecting it to member check. Through this process, the dialogue transcripts in which the participants participated were read to ascertain whether the words match what they actually intended and adequately represented their opinions. While engaging the discussants, the researchers used note-takings method to take account of 
the discussions that took place because participants declined to voice recording. Content analysis of the items was done on Nvivo version 11.0, a qualitative statistical package.

\title{
5. RESUlts
}

Research Question 1: What are the government safety nets programme available for teachers in schools in preparation for retirement? To answer this question, participants' responses were noted as discussed and then presented as follow:

\begin{abstract}
"We would have appreciated Nigerian governments if teaching is seen as a profession that illuminates other professions; and considered teachers as major part of their responsibilities that they are obliged to cater for in terms of regular payment of salary, other allowances and ideal social package that will enhance their living standard during and after service. But, it is a pity that Nigerian government at all levels have failed to live up to expectation in taking adequate care of us as teachers in terms of salary payment, promotion as and when due, regular payment of the allowances and social packages upon retirement. The most painful thing that some state government do is monthly deduction of $2.5 \%$ of pension scheme from our salary with the expectation that another $2.5 \%$ will be added by the state government but which wasn't added. It is unfortunate that these state governments only deduct $2.5 \%$ of our salary every month without remitting it into our pension accounts. In some states, the teachers there have even lost count of months the deductions were last remitted. This has affected our colleagues that have retired a lot because they are wallowing in poverty to the extent that they find it so difficult to cater for their family and their health needs. It is equally lamentably sad to have observed that even the cooperative thrift many of us engaged in, some state governments collected the entire contributions to run their government. It became so bad that some colleagues even retired without been able to access their entitlements including loans".
\end{abstract}

The interaction with the teachers and the principals showed that there is no ideal safety nets programme put in place for teachers in Nigerian schools in preparation for retirement. From their responses, it could be deduced that there is no any social package that may likely enhance the living standard of teachers when retired, let alone to safe them(teachers) from social and financial embarrassment upon their retirement.

Research Question 2: What are the personal safety nets of individual teachers in Nigerian schools? The participants responded that:

"It is very difficult for us to plan for our retirement days because we have met ourselves in a tight corner, we are only compelled to work and give our best for the states but the states failed to make us happy. Teachers' welfare here in Nigeria is nothing to the governments because we sometimes receive two months' salary in three months. Besides, the government does not consider teachers' motivation as something important because the last time many of us got ideal promotion we can't even recall. Though, in some states, we were promoted relatively every three years but the promotion does not reflect in our salaries. For instance, in some states, level 12 teachers are collecting the salary that is equivalent to what level 10 teachers should collect. From this current situation in Nigeria and inflation rate in the country, we are only trying to manage our salaries to ensure that basic things are taken care of. For now, we don't have any plan for retirement but trying to salvage current situation. When we get to the bridge, we can begin to plan on what to do to cross it'”.

The interaction with the teachers and the principals showed that there is no safety net programme put in place by individual teachers in Nigerian schools because the salary to plan on is not paid as and when due. The government pays teachers' salary any day of the month as may be considered appropriate.

Research Question 3: What are the differences in safety nets preparation between male and female teachers in Nigeria? The participants responded that: 
"We female teachers engage in some petty trades after school hours to ensure that we safe little to fall back on while retired. We male teachers only resign to faith that hard time is not forever, happy days will come again. We cannot dish something from nothing because the salary we are earning is not enough to meet up with the basic needs of the family let alone for business establishment. We believe that another government will come that will consider the needs and yearnings of the teachers a paramount thing. However, we still have some colleagues who operate 'Cabs' while some engage in farming, but majority are not really engaged in the real sense'.

From the interaction with the teachers and the principals, it could be established that the female teachers are a bit ready for the retirement than their male counterpart; as this is based on the fact that majority of the female teachers engage in some petty trades after school hours. These trades fetch them additional income to compliment irregular salary payment by the government and as a result, they are able to safe little for dry days., The responses of the male teachers showed that they are unable to engage in any business outside the teaching job because, the salary they earn is not enough to cater for the family needs let alone for business establishment. However, interaction with the participants (male \& female) established they practice subsistence farming so as to argument their take-homes.

Research Question 4: What are the problems associated with safety nets among teachers in Nigeria? To answer this, participants established that:

Nigerian governments do fondly claim that the states are facing financial crises as a result of plummet in the price of petroleum in 2016 that made it difficult for some states to meet up with the financial obligations for the teachers. But, the fact still remains that the failure of the state government to do the needful is as a result of executive recklessness in the states, poor political will and misplaced priority of whoever heads the state government. Our inability to enjoy even from the cooperative and thrift society we established for our private needs is another great challenge.

Arising from participants' interaction was the establishment of the major problem associated with safety nets among teachers in Nigeria-poor political will and executive financial recklessness.

\section{DISCUSSION}

To aid better discussion, efforts were made here to reflect on the research questions as raised to guide the study. The discussion of findings is presented under related subheadings as follow:

\section{Government safety nets programme available for teachers in Nigerian schools in preparation for retirement}

It was established that there is no ideal safety nets programme put in place for teachers in Nigerian schools by the government. This is because there is no any social package that may likely enhance living standard of the teachers while retired and to safe teachers from social and financial embarrassment upon their retirement. This finding is contrary to Kasuso (2015), who opined that safety nets are aimed at protecting citizens against vulnerability and risk of any kind ranging from vulnerability to income poverty, malnutrition, or natural disasters, which may affect different people in different ways, times and magnitudes. In addition, that safety nets frameworks in developing countries are premised on three basic pillars which are social prevention, social insurance and social assistance seems not applicable to the states here in Nigeria. Perhaps because this has not been established in the country for teachers. To buttress the finding, ILO (2000) maintained that safety nets is a government-provided anti-poverty benefit which is a major element of social assistance intended to assist people who have been unfavourably affected by shocks or other kinds of emergencies and not necessarily the poor. This could be in form of security, social protection and anti-poverty programmes.

\section{Personal safety nets of individual teachers in Nigerian schools}

The findings showed that there is no much safety net programme put in place by individual teachers in Nigerian schools because the salary on which to plan is not paid as and when due. Most state governments pay teachers' salary at a time considered convenient and subject to availability of funds. This indicates why some State governments pay monthly salary in arrears. This is in line with Beegle, 
Honorati, and Monsalve (2018) submission that safety nets are useful for social pensions which includes old-age social pensions, allowances, or benefits. Unlike social pensions, contributory pensions require payment in advance but there is always a littleto what anyone can do if government refuses to pay regularly. As observed by Loprest and Nightingale (2018), results emanating from this study showed non-compliance with the changes in structure and technology which should have assisted workers planning to retire. While ensuring adequate monitoring and enforcement of the current system to make sure that eligible workers receive their benefits, other measures must have taken into focus provision of temporary or transitional payment. This can be done by planning and organizing programmes that attempt in some ways to prepare retiree for life after retirement. Even with the non-payment of salaries on regular basis, the idea of looking elsewhere for loan would not have been unusual.

\section{The differences in safety nets preparation between male and female teachers in Nigeria}

It was established that the female teachers are a bit ready for the retirement than their male counterpart because majority of the female teachers engage in some petty trades after school hours. These trades fetch them additional income to compliment irregular salary payment by some State governments and as a result, they are able to safe little for dry days. However, subsistence farming seems to be practiced by the male teachers to argument the financial irregularities as observed. The submission of Pasadilla (2000) is in line with the findings that safety nets were introduced in form of loans, funding for displaced workers, calamity and housing loans, and emergency loans for whoever that is interested in it to make up for any short coming that arises. Pasadilla argues that women are more open to this because they like to raise loan to boost their petty business as they see it as opportunity to take their businesses to the next level. These soft loans as envisioned was to lessen the impact of poverty, protecting individuals, households and communities at large against uninsured risks of income and consumption. Risks can be attributed to the household (e.g. accidents or sudden death in a family), community (e.g. drought or famine) or nationwide (e.g. the Covid-19 pandemic, drought or global financial risks).

\section{The problems associated with safety nets among teachers in Nigerian schools}

It was established that the problem associated with safety nets among teachers in Nigeria were the poor political will and executive financial recklessness of some state governments. Nigerian governments seem to claim that the states are facing financial crises as a result of plummet in the price of petroleum which as a result have made it difficult for the states to meet up with their financial obligations. But, the fact still remains that the failure of the state government to do the needful remains the misplaced priorities, loss of motivation for teachers and executive financial recklessness in the states. This in line with Loprest and Nightingale (2018), that safety net programmes provide income, food, health care, housing, and other forms of support to some low-income people and families. This benefit supplements the earnings of low and moderate-income workers, varying the amount of the credit depending on earnings. Gentilini (2005) also submitted that the introduction of safety net programmes by government of any country is capable of promoting and providing support for work as it will help to increase returns for those with low wages. Moreover, connecting safety net programme recipients to quality education and training programmes that improve skills could lead to higher-wage jobs but the problem associated with it is inadequate distribution of wealth.

\section{CONCLUSION}

This study concludes that there is no safety nets programme put in place for teachers in Nigerian schools in preparation for retirement. Also, there is no much safety net programme put in place by individual teachers because the salary to plan on is not paid regularly; female teachers are a bit ready for the retirement than their male counterpart because majority of the female teachers engage in some petty trades after school hours. These trades fetch them additional income to complement irregular salary paid by the state governments. Moreover, the problem associated with safety nets among teachers in Nigeria is the issue of non-observance of agreement terms by the government which are as a result of misplaced priorities, poor political will and executive financial recklessness of some state governments. 


\section{RECOMMENDATIONS}

Based on the findings of the study, it is recommended that government should pay expected attention to social package of Nigerian teachers to save them from social and financial embarrassment while retired. Also, state governments should pay teachers' salary and other allowances regularly to aid preparation of teachers for retirement days. Besides, it is encouraged that both male and female teachers should cultivate habit of thrift to have something to fall back on while retired. Finally, the State governments should maintain a measure of financial discipline to help them cater for the needs of the teachers at retirement.

\section{REFERENCES}

[1] Adamolekun, A. (2011). A conceptual framework for social safety net; individualization of society and risk management. Tokyo: Keiso-shobo.

[2] Aiyede, E., Sha, P., Haruna, B., Olutayo, A., Ogunkola, E., \& Best, E. (2015). The Political economy of social protection policy uptake in Nigeria. Partnership for African Social and Governance Research Working Paper No. 002, Nairobi, Kenya.

[3] Beegle, K., Honorati, M., and Monsalve, E. (2018). Reaching the poor and vulnerable in Africa through social safety nets. Available at: https://elibrary.worldbank.org. Retrieved on 19th April, 2019.

[4] Gentilini, U. (2005). Mainstreaming safety nets in the social protection policy agenda: A new vision or the same old perspective? Journal of Agricultural and Development Economics, 2 (2), 133-157.

[5] International Labour Office (2000). World labour report 2000: Income security and social protection in a changing world. Geneva: ILO.

[6] International Labour Organization. (2008). LABORSTA Internet: Total economically active population. Retrieved April 12, 2019 from http://laborsta.ilo.org/

[7] Jurado, G. M. (2001). An integrated study of selected social safety net policies and programmes in Asia and the Pacific. Paper presented at the regional seminar on strengthening policies and programmes on social safety nets, ESCAP.

[8] Kasuso J. (2015). The role of health insurance in joint retirement among married couples, Industrial and Labour Relations Review, 64, 39-40.

[9] Loprest, P. \& Nightingale, D. (2018). The nature of work and social safety net. Washington, DC: Urban Institute.

[10] Monalve, D. (2018). Age discrimination legislation in the United States. Contemporary Economic Policy, 21,297-317.

[11] Moser, R. H. (1997). On Retirement. Annals of Internal Medicine. 127(2), 159 - 161.

[12] Nightingale, F. (2018). The social impact of Indonesian Economic Crisis, in TDRI 2000. Social impacts of the Asian Economic Crisis in Thailand, Indonesia, Malaysia and the Philippines. Bangkok: Ford Foundation.

[13] Nwajagu, (2007). Learned helplessness, discouraged workers, and multiple unemployment equilibria. The Journal of Socio-Economics, 35(6) 458-475.Oladunjoye, P. \& Omemu, F. (2015). Retirement: A blessing or a Curse? The Nigerian teachers' perceptions. Journal of Elementary Education, 23(2), 17-26.

[14] Olusegun, Oluwadamilola C. (2019) Safety Nets and Labour Force Retirement among Secondary School Teachers in Osun State. An unpublished M.A Ed thesis, Obafemi Awolowo University, Ile-Ife, Nigeria.

[15] Paitoonpong, S., Abe, S., \&Puopongsakorn, N. (2008). The meaning of social safety nets. Journal of Asian Economics. (Check for volume and page nos)

[16] Pasadilla, G. O. (2000). Social Impact of the Asian Crisis in the Philippines, in TDRI 2000. Social Impacts of the Asian Economic Crisis in Thailand, Indonesia, Malaysia and the Philippines. Bangkok: Ford Foundation.

[17] Shepherd, A. (2004). General review of current social protection policies and programmes. Paper prepared for DFID. London, UK.

[18] Subair, S. 'Tayo (2019) Retirement plan initiatives: Basic needs for life continuity. A paper presented at a 3-day training organised by Snowfield Consult for the Staff of Osun State College of Education, held at the Upper Springs Hotel and Suites, Iwaraja, State of Osun.

[19] Teranishi, J. (2005). A conceptual framework for social safety net; individualization of society and risk management. Tokyo: Keiso-shobo

[20] Vivian, J. (1994). Social safety nets and adjustment in developing countries. Occasional paper no. 1. World Summit for Social Development. Geneva: United Nations Research Institute for Social Development. 
[21] World Bank. (1990). World development report 1990: Poverty, World development indicators. Washington, D.C.: World Bank.

\section{AUTHORS' BIOGRAPHY}

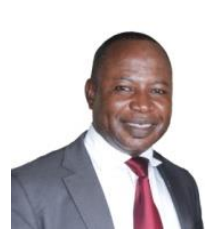

Dr. SUBAIR S' Omotayo, is a lecturer inthe Department of Educational Management and currently the Vice-DeanFaculty of Education Obafemi Awolowo University IleIfe, Nigeria. His area of specialization is Institutional Administration and Personnel Management with over a decade years of experience. To his credit are; publications in Journals and Books of Reading in both foreign and local outlets.

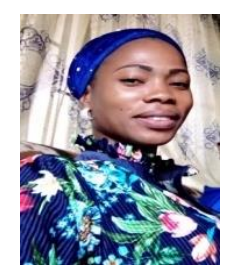

OLUWASEGUN Christianah Damilola, was a master student who studied Educational Administration inthe Department of Educational Management Obafemi Awolowo University Ile-Ife, Nigeria.

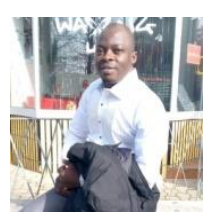

ALIYU M. Olasunkanmi, is a $\mathrm{PhD}$ student of Educational Planning in the Department of Educational Management Faculty of Education Obafemi Awolowo University Ile-Ife, Nigeria.

Citation: Subair, S. 'Tayo, Olusegun Oluwadamilola C., Aliyu, M. Olasunkanmi. "Safety Nets and Retirement Preparations of Teachers in Nigerian Schools" International Journal of Humanities Social Sciences and Education (IJHSSE), vol 8, no. 10, 2021, pp. 113-122. doi: https://doi.org/10.20431/2349-0381.0806011.

Copyright: (C) 2021 Authors. This is an open-access article distributed under the terms of the Creative Commons Attribution License, which permits unrestricted use, distribution, and reproduction in any medium, provided the original author and source are credited. 